\title{
Wireless Energy Transfer with Three-Phase Magnetic Field System: Experimental Results
}

\author{
L.F. Romba ${ }^{1}$, Stanimir S. Valtchev ${ }^{1}$, R. Melício ${ }^{2,3}$ \\ ${ }^{1}$ FCT, Universidade NOVA, Lisbon, Portugal \\ ${ }^{2}$ IDMEC/LAETA, Instituto Superior Técnico, Universidade de Lisboa, Lisbon, Portugal \\ ${ }^{3}$ Departamento de Física, Escola de Ciências e Tecnologia, Universidade de Évora, Portugal \\ e-mail:ruimelicio@gmail.com
}

\begin{abstract}
In this paper a three-phase magnetic field system is applied to the wireless power transfer system. The research is directed not only to the distribution of the magnetic field but to optimize the energy transfer efficiency, and to reduce the electromagnetic field influence to the surroundings. The development of the future intelligent transportation system depends on the electric mobility, namely, the individual or the public electric vehicles. It is crucial to achieve progress in the batteries and the battery charging, especially through a wireless power transfer technology. The study of the magnetic field is important in this technology. The energy transfer efficiency depends of the alignment, the size of the coils, the spatial orientation of the magnetic field, the detachment and the tilt between the windings.
\end{abstract}

\section{Key words}

WPT, magnetic field, magnetic resonant coupling, inductive power transfer, experimental results.

\section{Introduction}

The demand for sources of sustainable energy, the shortage of fossil fuels and the need for carbon footprint reduction have resulted in a global awareness of the importance of alternative energy sources and efficiency in the use of energy [1,2]. Particularly the internal combustion engines have become one of the major contributors for global greenhouse gases. Distributed generation, the increase of electricity demand, particularly the introduction of electrical vehicles (EV), will drive upcoming concerns on nowadays power systems about the ability to encompass with the future $[3,4]$. The EV has a negative impact on the power systems in terms of power outages, voltage fluctuations, harmonics pollution and system stability [5].

The ecological vehicle, i.e., electric vehicle is the international tendency in the automobile industry. With the electric vehicle, the battery manufacturing has seen huge growth over the past few years in portable, rechargeable battery packs.

Recently there has been a significant effort to develop new battery charging systems, accompanying the evolution of the battery manufacturing technology. The main purpose of the various systems of battery charging has been to increase the charge capacity and speed [6].

These needs are more evident in the applications for pure $\mathrm{EV}$, also known as battery electric vehicle (BEV), and for hybrid electric vehicles (HEV), both for individual or collective transport [6]. The new charging systems have been tested and installed in various cities, making it easier the use of this type of vehicles. Installed equipment allows, just as in normal fuel pumps, the self-service, which implies that it should be practical and safe to use $[6,7]$.

Maxwell, Henry Poynting and Nikola Tesla studies, that have been forgotten for about a century, gained a new importance with the results obtained by various researchers, especially the MIT team, which managed to show surprising results in electric energy transmission without contact, i.e., wireless power transfer (WPT) systems [8-10]. The WPT systems can be generally, divided into two categories, depending on the range that allow transmitting electric power: near-field, i.e., short range and far-field, i.e., long range [9-11].

The WPT near-field systems use the electric field or the magnetic field to transfer energy in short-range or in midrange.

The far-field technologies make use of microwave radiation or laser energy to transfer high power over long distances. However, those technologies require a direct visual contact for the transmission and large antennas, which are impractical in EV applications [11,12].

In the case of electric field as a transporter of energy (Capacitive Power Transfer or CPT), the main advantage is that the energy transfer is not affected by metal barriers and this method claims lower electromagnetic interference (EMI) [11]. However, the permittivity of the air is low, resulting in insufficient coupling capacitance, so the power transfer is very low and is sensitive to the 
air-gap distance between the coupling plates and its changes [12].

The magnetic field technology for energy transfer is possible in two main implementations: inductive power transfer (IPT) and magnetic resonant coupling (MRC) [13]. The IPT technology offers the possibility of transferring tens of $\mathrm{kW}$ but it is very sensitive to the airgap size. Even by a few $\mathrm{cm}$ of variation, it shows a significant variation of losses. The MRC technology applying higher internal voltages is less sensitive to larger air-gaps and it can extend the air-gap range to tens of $\mathrm{cm} \quad[12,14]$. Thus, the magnetic field WPT technologies have been identified as the most viable for EV battery charging [14].

The MRC is a process for WPT, using LC resonance, series or parallel, between the transmitter and the receiver. The primary and the secondary coils should have the same resonant frequency [11].

The three-phase system WPT with MRC process has three advantages [15]:

1) a high power capacity;

2) a relatively simple circuit compared to the same power capacity in single phase systems;

3) a capability to transfer continuous power without ripple.

The three-phase system is more effective for increasing capacity of MRC, up to $10 \mathrm{~kW}$. Although $10 \mathrm{~kW}$ is already realized in magnetic induction (heating), but when air-gap between the transmitter and receiver is larger than $0.1 \mathrm{~m}$ the transfer efficiency is low. The magnetic resonant coupling has the advantage of being more efficient when energy is transferred at a larger airgap. For example, the efficiency is $90 \%$ at air-gap of $0.5 \mathrm{~m}$, as it was already experimentally proven [14,15].

The tank circuits are constituted by coils and capacitors, the dielectric strength of these devices is a limitation, especially at circuits with high quality factor $\mathrm{Q}$. The voltages generated in these circuits, at the resonance frequency, are very high [14].

The solution with three-phase systems, has other advantage because for the same transmitted power, the system works with voltages $1 / \sqrt{3}$ lower than the monophasic systems [14,15].

The energy transfer process depends on the variation of the flux. This variation is generated by a high frequency alternate excitation. The high frequency alternate excitation is used to charge a battery, and for this should be rectified and filtered. The DC ripple voltage of the monophasic systems is always higher as compared with DC ripple voltage of the three-phase systems [15].

The behaviour of the magnetic field is important, as it is the mechanism to transfer the electrical energy in WPT systems. In the power systems a three-phase system is used when it is necessary to transfer large electrical power. The same procedure should be used in WPT systems [14].

This paper is organized as follows. Section II presents the magnetic field and the main modelling proposed. Section III deals with the prototype built in the Laboratory and the experimental results. Section IV presents the conclusions.

\section{Modelling}

The basis of WPT is the magnetic field variation. The magnetic field is generated in the transmitter coil, i.e., primary and it is received in the receiver coil, i.e., secondary. An electromotive force (emf) is induced in the coil when the magnetic flux through this coil varies, known as the Faraday Low and is given by

$E=-\frac{d \Phi}{d t}$

where $E$ is the emf, $\Phi$ is the magnetic flux.

Generalizing (1) to a coil with $N$ number of the turns is given by

$E=-N \frac{d \Phi}{d t}$

The mutual inductance $M$ between the primary and the secondary is given by

$M=\frac{\mathrm{N}_{\mathrm{s}}}{\mathrm{N}_{\mathrm{p}}} \frac{d \Phi_{m}}{d i_{p}}$

where $N_{s}$ is the number of the turns of the secondary, $\mathrm{N}_{\mathrm{p}}$ is the number of turns of the primary, $\Phi_{m}$ is the magnetic flux linking both coils, $i_{p}$ is the instantaneous current that flows through the primary coil.

This means that mutual inductance between the two coils is proportional to the instantaneous variation of the flux linking to the one coil $\Phi_{m}$ due to an instantaneous current variation $i_{p}$ through the primary coil.

The mutual inductance, in terms of the inductance of the primary and the secondary, respectively is given by

$M=k\left(L_{p} L_{s}\right)^{1 / 2}$

where $k$ is the coupling coefficient, $L_{p}$ is the inductance of the primary, $L_{s}$ is the inductance of the secondary.

The coupling coefficient is given by

$k=\frac{\Phi_{m}}{\Phi_{p}}$

where $\Phi_{p}$ is the magnetic flux generated by the primary.

\section{Experimental Results}

The study in this paper shows the behaviour of the magnetic field of a prototype built in the Laboratory of Power Electronics, Faculdade de Ciências e Tecnologia, Universidade Nova de Lisboa, Portugal. The power systems is a three-phase system in a star electrical 
connection at the frequency of $50 \mathrm{~Hz}$. For the prototype, the geometric configuration of the primary has three coils and has been placed in two different configurations delta or star. The magnetic field data were collected in both geometrical configurations, i.e., delta and star, respectively, that enables to choose the best configuration.

The primary coils are formed by three coils. Each coil was manufactured by wounding with 110 turns in two layers, the first layer with 60 turns and the second layer with 50 turns. Each coil has the length of $180 \mathrm{~mm}$, the thickness of $60 \mathrm{~mm}$ and the height of $300 \mathrm{~mm}$. The primary coils are identified by colours: red, yellow and white.

Table I summarizes the data measured for the primary windings.

Table II summarizes the data for the inductive reactance and the impedance measured for the primary windings.

The core of the primary coils consists of the laminated ferromagnetic material, cylindrical shape, with the diameter of $28 \mathrm{~mm}$ and the length of $130 \mathrm{~mm}$.

Table I. - Data Measured for the Primary Windings

\begin{tabular}{|c|c|c|}
\hline Coil & $\begin{array}{c}\text { Inductance } \\
{[\mathrm{mH}]}\end{array}$ & $\begin{array}{c}\text { Resistance } \\
{[\Omega]}\end{array}$ \\
\hline Red & 8.6 & 1.7 \\
\hline Yellow & 8.66 & 1.6 \\
\hline White & 9.43 & 1.6 \\
\hline
\end{tabular}

Table II. - Primary, Inductive Reactance and Impedance

\begin{tabular}{|c|c|c|}
\hline Coil & $\begin{array}{c}\text { Inductive reactance } \\
{[\Omega]}\end{array}$ & $\begin{array}{c}\text { Resistance } \\
{[\Omega]}\end{array}$ \\
\hline Red & 2.7 & 3.19 \\
\hline Yellow & 2.72 & 3.16 \\
\hline White & 2.96 & 3.37 \\
\hline
\end{tabular}

The coil probe of the prototype, i.e., the secondary is formed by a freely movable coil. The coil probe was manufactured by wounding 180 turns, 4 layers with 40 turns each and the last with 20 turns, with the inductance of $3.56 \mathrm{mH}$ and the resistance of $0.7 \Omega$. The core consists of the laminated ferromagnetic material, cylindrical shape, with the diameter of $28 \mathrm{~mm}$ and the length of $130 \mathrm{~mm}$.

The prototype is shown in Fig. 1.

To conduct the tests a platform was built with a nonferromagnetic material, namely Kline material, with the following dimensions $1000 \mathrm{~mm}$ of length and $700 \mathrm{~mm}$ of width. The coils, platform and probe coil are shown in Fig. 2.

In Fig. 2, over the platform surface two sets of lines was charted, the first set are lines centered, the second set are radial lines defining successive angles of $30^{\circ}$. The angles are marked on the radial lines at distance of $100 \mathrm{~mm}$.

With the prototype was performed a significant set of tests that enables the mapping of the magnetic field, in $\mathrm{X}$ and $\mathrm{Y}$ coordinates. For the tests, the measured emf values at each radial distance were obtained in steps of $30^{\circ}$. The radial distances were of $50 \mathrm{~mm}, 100 \mathrm{~mm}$ and $150 \mathrm{~mm}$.

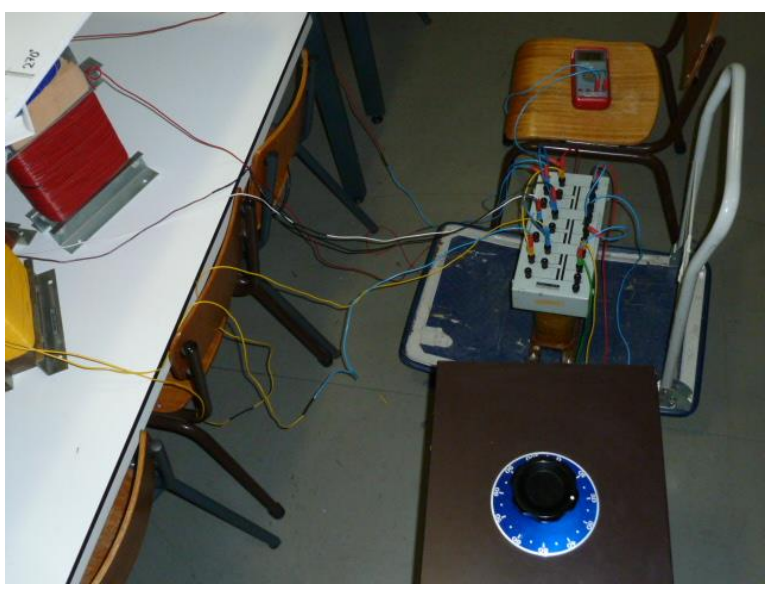

Fig. 1. Prototype built.

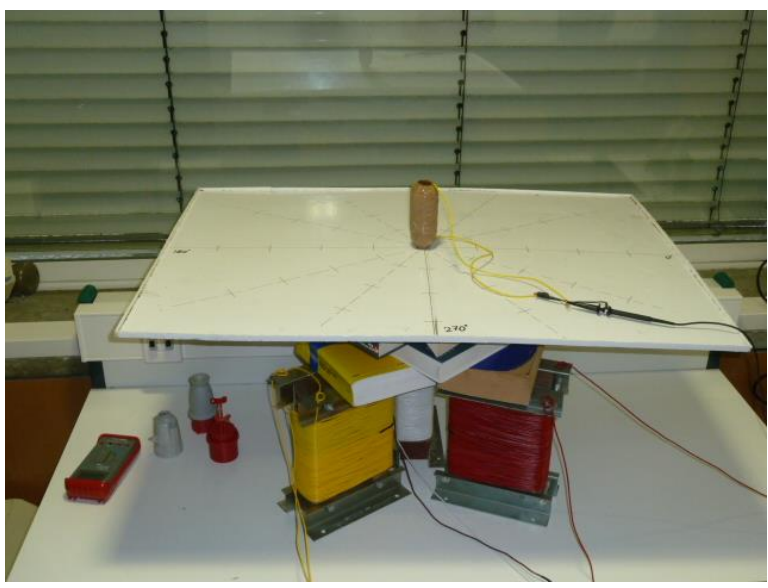

Fig. 2. Coils, platform and probe coil to conduct the tests.

The tests were conducted for the primary input voltages of $20 \mathrm{~V}$ and of $30 \mathrm{~V}$. The geometric configurations of the primary coils are placed in delta or star, respectively. The probe coil is placed in two positions: vertical position or horizontal and longitudinal position in respect to radial lines.

Table III summarizes the currents in each primary coil for the input voltages of $20 \mathrm{~V}$ and of $30 \mathrm{~V}$ applied by a transformer.

Table III. - Primary, currents in each primary coil

\begin{tabular}{|c|c|c|}
\hline Coil & $20 \mathrm{~V}$ & $30 \mathrm{~V}$ \\
\hline Red & $\begin{array}{c}\text { Current } \\
{[\mathrm{A}]}\end{array}$ & $\begin{array}{c}\text { Current } \\
{[\mathbf{A}]}\end{array}$ \\
\hline Yellow & 6.26 & 9.40 \\
\hline White & 6.34 & 9.51 \\
\hline
\end{tabular}

Primary coils placed in star configuration and coil probe in vertical position. The emf values are shown in Fig. 3. Fig. 3 shows: a) input voltage of $20 \mathrm{~V}$ - the emf at the radius $50 \mathrm{~mm}$ (blue), at the radius $100 \mathrm{~mm}$ (orange) and at the $150 \mathrm{~mm}$ (gray); b) input voltage of $30 \mathrm{~V}$ - the emf at the radius $50 \mathrm{~mm}$ (blue), at the radius $100 \mathrm{~mm}$ (orange) and at the $150 \mathrm{~mm}$ (gray). 
Primary coils placed in delta configuration and coil probe in vertical position. The emf values are shown in Fig. 4. Fig. 4 shows: a) input voltage of $20 \mathrm{~V}$ - the emf at the radius $50 \mathrm{~mm}$ (blue), at the radius $100 \mathrm{~mm}$ (orange) and

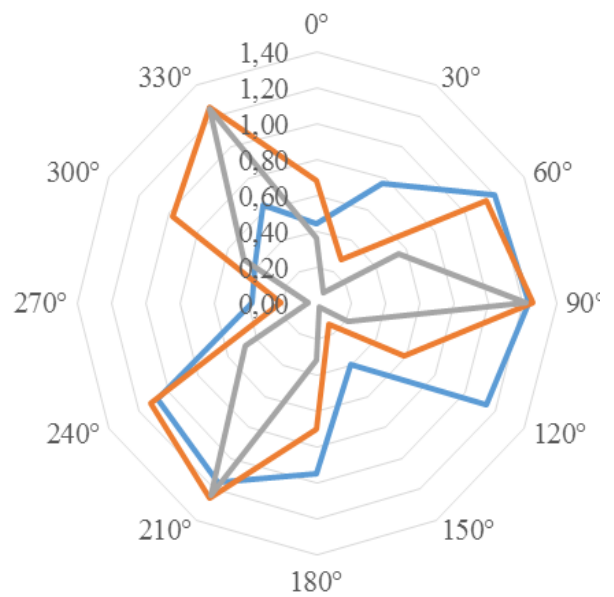

a) at the $150 \mathrm{~mm}$ (gray); b) input voltage of $30 \mathrm{~V}$ - the emf at the radius $50 \mathrm{~mm}$ (blue), at the radius $100 \mathrm{~mm}$ (orange) and at the $150 \mathrm{~mm}$ (gray).

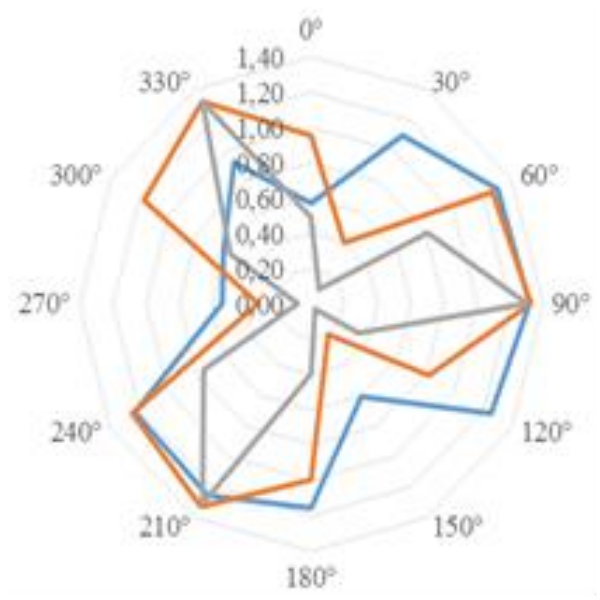

b)

Fig. 3. The emf, Primary placed in star, probe coil in vertical position: a) $20 \mathrm{~V}$; b) $30 \mathrm{~V}$.

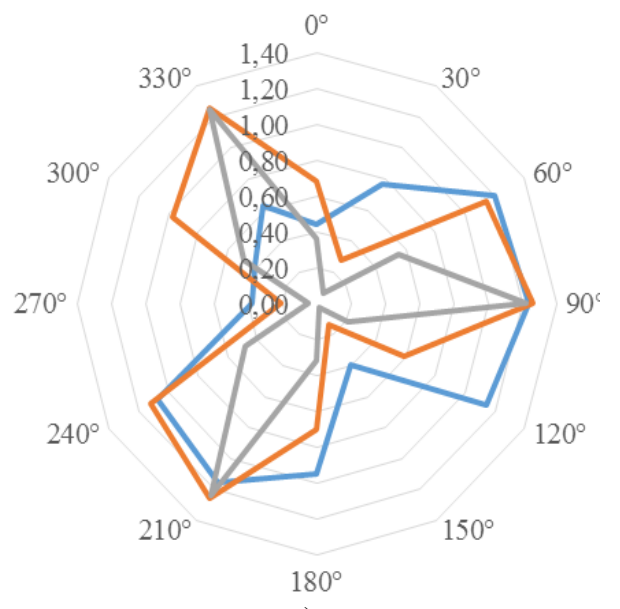

a)

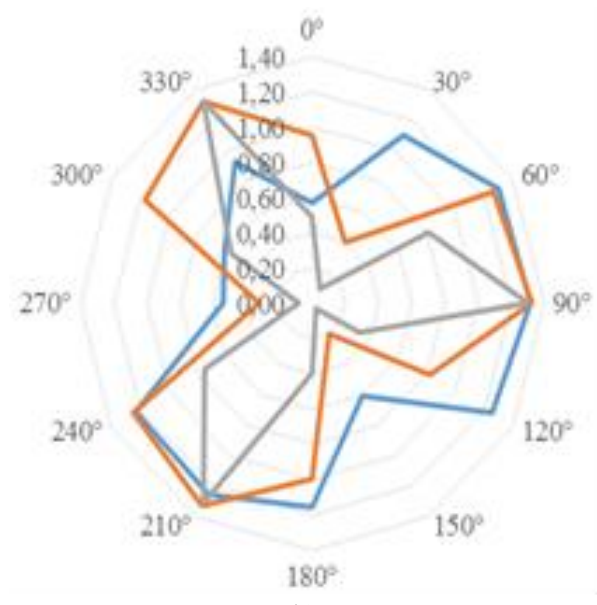

b)

Fig. 4. The emf, Primary placed in delta, probe coil in vertical position: a) $20 \mathrm{~V}$; b) $30 \mathrm{~V}$.

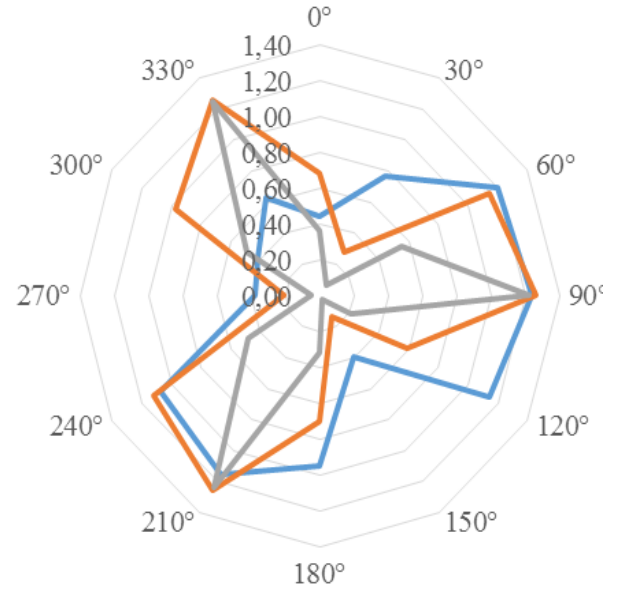

a)

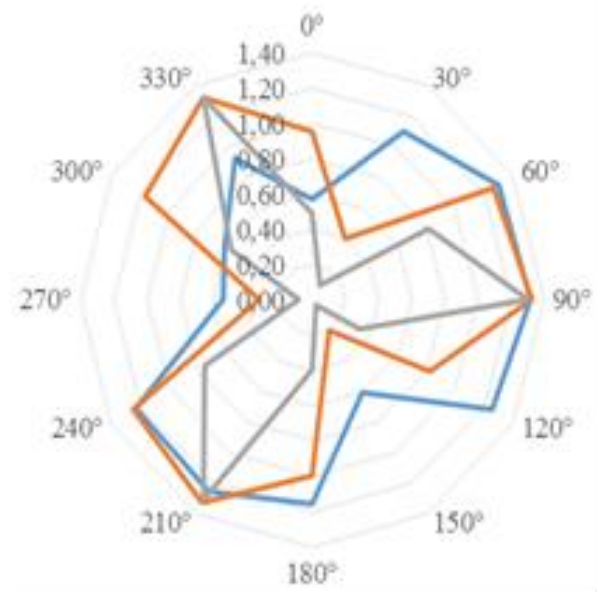

b)

Fig. 5. The emf, Primary placed in star, probe coil in horizontal and longitudinal position: a) $20 \mathrm{~V}$; b) $30 \mathrm{~V}$. 
Primary coils placed in star configuration and coil probe in horizontal and longitudinal position in respect to radial lines. The emf values are shown in Fig. 5 .

Fig. 5 shows: a) input voltage of $20 \mathrm{~V}$ - the emf at the radius $50 \mathrm{~mm}$ (blue), at the radius $100 \mathrm{~mm}$ (orange) and at the $150 \mathrm{~mm}$ (gray); b) input voltage of $30 \mathrm{~V}$ - the emf at the radius $50 \mathrm{~mm}$ (blue), at the radius $100 \mathrm{~mm}$ (orange) and at the $150 \mathrm{~mm}$ (gray).

Fig. 3 and Fig. 4 show that the emf values in the probe are higher, when the input voltage increases, as it was expected.

However, show that the highest emf values are reached at the radius $100 \mathrm{~mm}$ (orange). This is more evident, when compares Fig. 3b) and Fig. 4b) that correspond to the same input voltage $(30 \mathrm{~V})$, but at two different geometric configurations. The magnetic field achieves higher values and more uniform in the delta configuration.

Fig. 5 and Fig. 6 show that the emf values are higher at the radius $50 \mathrm{~mm}$ (blue). For the primary star geometric configuration allows that the magnetic field lines closes in the neighbourhood of the magnetic poles.

Due to the cross-section be rectangular core, the magnetic field lines have the highest density at the ends of the core. This fact, justifies the obtained highest emf values in the lowest radius $(50 \mathrm{~mm})$. Also, the higher emf values are achieved whit the probe in horizontal and transversal position. Fig. 4, primary in delta geometric configuration, the covered area by the magnetic field is larger.

\section{Conclusion}

The primary magnetic cores placed in delta geometric configuration (triangular disposition), is the best solution, as can be confirmed in Fig. 4b), orange line. In this case there is a limitation: the highest induced electromotive force values corresponding to the highest intensity of the magnetic induction are obtained only close to the circumference, which corresponds to the cores geometric position.

The primary magnetic cores placed in star geometric configuration show the highest magnetic induction values at the much closer distance from the center as can be confirmed in Fig. 5b), blue line. The magnetic intensity inside the area covered by magnetic field in Fig. 5b) is slightly higher than the magnetic field intensity inside the magnetic field area in Fig. 4b).

The primary placed in delta, probe coil in vertical position $(30 \mathrm{~V})$ shown in Fig. 4b) is less sensitive to any non-alignment than the primary placed in star, probe coil in horizontal and longitudinal position $(30 \mathrm{~V})$ shown in Fig. 5b).

\section{Acknowledgments}

This work is funded by Portuguese Foundation for Science \& Technology, through IDMEC, under LAETA, project UID/EMS/50022/2013.

\section{References}

[1] L. Schaefer, "Editorial", Sustainable Energy Technologies and Assessments, vol. 1, pp. 1-2, March 2013.

[2] N.C. Batista, R. Melicio, J.C.O. Matias and J.P.S. Catalão, "Self-start performance evaluation in Darrieus-type vertical axis wind turbines: methodology and computational tool applied to symmetrical airfoils", in: International Conference on Renewable Energies and Power Quality, 1-6, Las Palmas de Gran Canaria, Spain, April 2011.

[3] N.C. Batista, R. Melicio, J.C.O. Matias and J.P.S. Catalão, "ZigBee standard in the creation of wireless networks for advanced metering infrastructures", in: 16th IEEE Mediterranean Electrotechnical Conf., 220-223, Yasmine Hammamet, Tunisia, March 2012.

[4] R. Melicio, V.M.F. Mendes and J.P.S. Catalão, "Computer simulation of wind power systems: power electronics and transient stability analysis", in: Int. Conf. on Power Systems Trans., 1-7, Kioto, Japan, June 2009.

[5] R. Melício, V.M.F. Mendes, J.P.S. Catalão, "Modeling and simulation of wind energy systems with matrix and multilevel power converters", IEEE Latin America Transactions, vol. 7(1), pp. 78-84, March 2009.

[6] D. Matthias Galus, R.A. Waraich, F. Noembrini, K. Steurs, G. Georges, K. Boulouchos, K.W. Axhausen, and G. Andersson, "Integration power system, transport systems and vehicle technology for electric mobility impact assessment and efficient control", IEEE Trans. on Smart Grid, vol. 32(2), pp. 934-949, June 2012.

[7] A. Brecher, and D. Arthur, "Review and evaluation of wireless power transfer (WPT) for electric transit applications", in: U.S. Depart. of Transpor., August 2014.

[8] S. Li, and C.C. Mi, "Wireless power transfer for electric vehicle applications", IEEE Journal of Emerging and Selected Topics in Power Electron., vol. 3(1), pp. 4-17, March 2015.

[9] A. Kurs, A. Karalis, R. Moffatt, J.D. Joannopoulos, P. Fisher, and M. Soljačič, "Wireless power transfer via strongly coupled magnetic resonances", Science, vol. 317, pp. 83-86, July 2007.

[10] C. Qiu, K.T. Chau, T.W. Ching, and C. Liu, "Overview of wireless charging technologies for electric vehicles", Journal of Asian Electric Vehicles, vol. 12(1), pp. 16791685, June 2014.

[11] X. Mou, and H. Sun, "Wireless power transfer: survey and roadmap", in 81th IEEE Vehicular Technology Conference, 1-5, Glasgow, UK, May 2015.

[12] Y. Park, J. Kim, and K.-H. Kim, "Magnetically coupled resonance wireless power transfer (MR-WPT) with multiple self-resonators". In: Wireless Power Transf. Principles and Engineering Explorations, K.Y. Kim editor, Intech, 51-64, China, 2012.

[13] S.S. Valtchev, E.N. Baikova, and L.R. Jorge, "Electromagnetic field as the wireless transporter of energy". In: Electronics and Energetics, Facta Universitatis, vol. 25(3), 171-181, Nis, Serbia, December 2012.

[14] J. Shin, S. Shin, Y. Kim, S. Ahn, S. Lee, G. Jung, S.-J. Jeon, and D.-H. Cho, "Design and implementation of shaped magnetic-resonance-based wireless power transfer system for roadway-powered moving electric vehicles", IEEE on Ind. Elect., vol. 61, pp. 1179-1192, April 2013.

[15] Y. Tanikawa, M. Kato, T. Imura, and Y. Ori, "Experiment of magnetic resonant coupling three-phase wireless power transfer", in: World Electric Vehicle Symposium and Exhibition, 1-8, Barcelona, Spain, November 2013. 